\section{SIGNIFICANCE OF RACIAL DIFFERENCES}

$\mathrm{D}$ R. G. M. MORAN'T'S informed and clearly reasoned pamphlet on "The Significance of Racial Differences"* makes an important contribution to the series of publications on the question of race published by the United Nations Educational, Scientific and Cultural Organization. Racial differcnces, their extent and their significance, are burning questions to-day when racial stresses are rampant. What has been established by a century of scientific inquiry should be more widely known, and the methods of approach to such questions more widely understood. "Popular views of the matter are still nebulous enough to be swayed by anyone who chooses, for his own ends, to spread 'racial' dogmas which cannot readily be proved true or false."

Racial differences, physical and mental, have indeed been a subject for literary discussion for two thousand years and more. But a fundamental weakness is that it has no agreed systematic method of considering such questions of group difference. The classes of evidence chosen for emphasis and the choice and interpretation of items in those classes are usually such as best fit some general theory of the writer's ; they offer a wide field for bias and produce many contradictory conclusions. But certain tendencies are general : to regard as 'racial' many differences that are environmental or cultural ; to reduce, for simpler thinking, the variety that every group ( xhibits to the uniformity of a single type; to endow that type with the more extreme and striking attributes of a few, rather than with those of the group as a whole ; and to assume that groups which are markedly different in regard to some obvious physical attribute must have certain marked differences in mental make-up.

Scientific inquiry, on the other hand, whether into the physical, physiological or mental constitution of human groups, has the same agreed basic method of approach, which the author describes. By techniques of analysis which compare groups as a whole, it has established for many attributes (or 'characters'), especially physical, the actual extent of racial differences. "The ways in which men differ are of small account compared with the ways in which they are alike, but the former make up the class defining individual and group distinctions."

Though the physical differences between groups may often have little practical importance-apart from the influence on attitudes and intercourse of any that make very obvious distinctions between peoples-the results of the study of the physical characters have this advantage : that most characters of form, size or colour are mainly (and blood groups are believed to be entirely) determined by hereditary factors; whereas the outward manifestations of mental characters are determined to a considerable extent by experience and social environment. In both cases it is the hereditary, the racial, factors that are in question, and the ampler findings in regard to physical characters can throw light on the more complex question of the mental differences between racial groups.

* "The Signiflcance of Racial Differences". (The Race Question in Modern Science.) By Dr. G. M. Morant. Pp. 48. (Paris: Unesco: London: H.M.S.o., 1952.) $18.6 d$. ; 25 cents ; 75 francs.
Within all racial groups for which there are adequate records over the past seven thousand years, physical variation as recorded is of much the same order: rather less, as a rule, in the earlier series than the later, but not much; rather more in modern Europe than elsewhere, but with exceptions. 'There is considerable variation in group averages; but for very few 'continuous variables', apart from characters of colour and hair form, can groups be found the distributions of which do not overlap. Even in stature, and taking groups at opposite ends of the range, the tallest Congo pygmy is about as tall as the shortest Dinka; and in pairs of racial series selected at random about one in three would differ in average height by less than $4 \mathrm{~cm}$. Dr. Morant, by a slip, says "about one in 130 ' (p. 32), a figure contradicted by the evidence of his distributions; also, in stating (p. 41) that no other measurement is known to differentiate racial populations as effectively as stature and cephalic index, he overlooks nosebreadth, which differentiates more effectively than either-hand-breadth probably too (Man, 50, No. 14). These errors do nothing to weaken his argument. For almost all metric characters, inter-racial variation is less than intra-racial, and the distributions for even the most divergent groups overlap widely, so that a large proportion of the individuals belonging to one could belong to either.

Valid comparisons between group averages for innate, hereditary, mental ability and disposition are difficult to make for racial groups whose mental experience is very different; but mental tests have at least shown a wide range of variation in any group tested, and-allowing for differences of backgroundwide overlap in group distributions. A rule found to apply to all forms of life is that variation within inter-breeding groups is associated with variation between such groups; and it is improbable that man's mental characters, unlike his physical, are an exception. "The general inference is that there are racial differences in mentality, although clear demonstration of them-regarding particular characters and particular pairs of populations-is not available yet". The differences are not likely to be all in favour of the same groups. Nor does it necessarily follow that a wide average difference in some physical trait is associated with a wide average difference in some mental trait. Also, the average mental differences may be small : existing evidence suggests "that group diversity tends to be less in degree for mental tests than for body measurements"- if less, not less significant.

Dr. Morant points out an aspect of group difference that, for mental characters, may make a distinction of importance. Two overlapping distributions of which the mean values are not far apart are yet likely to differ considerably in their relative frequencies of individuals having extreme values of the character. "There may be almost equal proportions of stupid, mediocre and able people in two populations; even so, exceptional ability may be found with a frequency of 1 in 1,000 in one group and with a frequency of 1 in 10,000 in the other. Having a larger proportion of exceptionally able members may be a factor which tells decisively in favour of a population in the course of centuries or milleniums." One might go further than does Dr. Morant in this informative and thoughtful pamphlet: at turning points in a nation's history it may tell decisively, though briefly, on its whole future course.

M. L. TIIDESLEY 